\title{
Association between Lipoprotein(a) Concentration and Adverse Cardiovascular Events in Vietnamese Patients with Acute Myocardial Infarction: An observational cohort study
}

\author{
Sy Van Hoang 1,2, Quang Duy Dang Pham ${ }^{3}$, Kha Minh Nguyen ${ }^{1,2}$, Khoa Le Anh Huynh ${ }^{4}$, Tra Thanh Ngo ${ }^{5}$, \\ Huu Nhat Minh Le ${ }^{6}$, Hai Phuong Nguyen Tran ${ }^{7, *}$
}

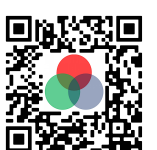

Use your smartphone to scan this QR code and download this article

${ }^{1}$ Department of Internal Medicine, Faculty of Medicine, University of Medicine and Pharmacy at Ho Chi Minh City, Ho Chi Minh City 700000, Viet Nam

${ }^{2}$ Department of Cardiology, Cho Ray Hospital, Ho Chi Minh City 700000, Viet Nam

${ }^{3}$ Department of Cardiology, University Medical Center, University of Medicine and Pharmacy at Ho Chi Minh City, Ho Chi Minh City 700000, Viet Nam

${ }^{4}$ Department of Biostatistics, Virginia Commonwealth University School of Medicine, Virginia, USA

${ }^{5}$ Cardiovascular Research Department, Methodist Hospital, Merrillvill, Indiana, USA

${ }^{6}$ Methodist Hospital, Merrillvill, Indiana, USA

${ }^{7}$ Department of Cardiology Intervention, Cho Ray Hospital, Ho Chi Minh City 700000, Viet Nam

Correspondence

Hai Phuong Nguyen Tran, Department of Cardiology Intervention, Cho Ray Hospital, Ho Chi Minh City 700000, Viet Nam

Email: tnphuonghaibvcr@gmail.com

History

- Received: Nov 16, 2021

- Accepted: Jan 26, 2022

- Published: Jan 30, 2022

DOI : 10.15419/bmrat.v9i1.724

\section{Check for updates}

\section{Copyright}

(๑) Biomedpress. This is an openaccess article distributed under the terms of the Creative Commons Attribution 4.0 International license.

\begin{abstract}
Background: This study aimed to evaluate serum lipoprotein(a) concentrations in Vietnamese patients with acute myocardial infarction and to investigate the relationship between high serum concentrations of lipoprotein(a) and major adverse cardiovascular events after acute myocardial infarction. Methods: We conducted a prospective cohort study that included data from 199 patients with acute myocardial infarction admitted to the Cardiology Department, Cho Ray Hospital, Vietnam. Data on demographics, and hematologic, and biochemical blood test results, including serum lipoprotein(a) concentrations and coronary angiography results, were collected. All major cardiovascular adverse events (MACE) were defined as cardiovascular mortality, non-fatal myocardial infarction, and non-fatal ischemic stroke in hospital 30 days after discharge. Results: In patients with acute myocardial infarction, serum concentrations of lipoprotein(a) were not normally distributed, and skewed to the right, with a median of $17.8 \mathrm{mg} / \mathrm{dL}$, interquartile range (IQR) 7.6-34.5 $\mathrm{mg} / \mathrm{dL}$. Overall, $29.1 \%, 17.1 \%, 12.6 \%$, and $6.5 \%$ of patients had a serum lipoprotein(a) concentration of $\geq 30, \geq 50, \geq 70$, and $\geq 90 \mathrm{mg} / \mathrm{dL}$, respectively. Patients with a serum lipoprotein(a) concentration of $\geq 50 \mathrm{mg} / \mathrm{dL}$ had a higher BMI $(p=0.04)$, a higher rate of non-ST-elevation myocardial infarction (NSTEMI) ( $p=0.035)$, a lower GRACE score ( $p=0.038)$, higher levels of total cholesterol, high-density lipoprotein cholesterol (HDL-C) and unadjusted low-density lipoprotein cholesterol (LDL-C) concentrations ( $p=0.002,0.015,<0.001$, respectively), and a higher rate of three-vessel disease $(p=0.023)$ compared to patients with a serum lipoprotein(a) concentration $<50 \mathrm{mg} / \mathrm{dL}$. The relative risk between lipoprotein(a) $\geq 50 \mathrm{mg} / \mathrm{dL}$ and MACE was 2.37 . Conclusions: Patients with acute myocardial infarction and serum lipoprotein(a) $\geq 50 \mathrm{mg} / \mathrm{dL}$ were more likely to have NSTEMI and a lower GRACE score. Lipoprotein(a) $\geq 50 \mathrm{mg} / \mathrm{dL}$ at the time of acute myocardial infarction was not associated with in-hospital MACE, 30-days-after-discharge MACE, nor with all-cause mortality within 6 months of study follow-up.
\end{abstract}

Key words: acute myocardial infarction, cohort study, LDL-C, lipoprotein(a), MACE

\section{INTRODUCTION}

Low-density lipoprotein cholesterol (LDL-C) has long been a focus of treatments aimed at reducing the risk of adverse cardiovascular events ${ }^{1}$. In addition, lipoprotein(a) is considered remarkable for its dual pathogenicity as a pro-atherosclerotic and prothrombotic agent ${ }^{2}$. Lipoprotein(a) is one of six types of human lipoprotein. The others are chylomicron, high-density lipoprotein (HDL), intermediatedensity lipoprotein (IDL), low-density lipoprotein (LDL), and very low-density lipoprotein (VLDL). Lipoprotein(a) is comprised of an LDL particle that contains a single molecule of apolipoprotein B100 and another protein, apolipoprotein $(a)^{3-6}$.

In the general population, meta-analyses of prospective population-based studies of adults show an in- creased risk of coronary heart disease and myocardial infarction at lipoprotein(a) concentrations greater than $30 \mathrm{mg} / \mathrm{dL}$, and an increased risk of ischemic stroke at concentrations greater than $50 \mathrm{mg} / \mathrm{dL}^{2,4,7}$. However, in high-risk populations, such as patients with established atherothrombotic disease, there is ongoing controversy regarding the influence of elevated lipoprotein(a) on cardiovascular risk ${ }^{8}$. In a meta-analysis by Willeit et al., based on seven randomized, placebo-controlled, statin-outcomes trials, the association between both baseline (no statin) and statin treatment, the association of lipoprotein(a) with cardiovascular disease risk was approximately linear, with an increased risk at lipoprotein(a) values of $\geq$ $30 \mathrm{mg} / \mathrm{dL}$ for the baseline group, and $\geq 50 \mathrm{mg} / \mathrm{dL}$ for the statin group ${ }^{9}$. These findings suggest that patients with serum lipoprotein(a) of $\geq 50 \mathrm{mg} / \mathrm{dL}$, who

Cite this article : Hoang S V, Pham Q D D, Nguyen K M, Huynh K L A, Ngo T T, Le H N M, Tran H P N. Association between Lipoprotein(a) Concentration and Adverse Cardiovascular Events in Vietnamese Pa-tients with Acute Myocardial Infarction: An observational cohort study. Biomed. Res. Ther., 2022; 9(1):4873-4883. 
currently use statins, may benefit from lowering their serum lipoprotein(a) levels. Therefore, we used 50 $\mathrm{mg} / \mathrm{dL}$ as the cut-off value in our study, instead of 30 $\mathrm{mg} / \mathrm{dL}$, which is the manufacturer's cut-off value, as well as a common cut-off value in studies based on the general population.

No approved pharmacologic therapies to lower lipoprotein(a) concentrations are currently available ${ }^{10}$. Physical activity, diet, and statin use have not been shown to affect serum lipoprotein(a) concentrations 9,11 . Various therapies have been suggested to treat elevated concentrations of lipoprotein(a), including niacin, PCSK9 inhibitors, and CETP inhibitors; however, no randomized controlled trial has demonstrated that a reduction in lipoprotein(a) leads to a lower risk of cardiovascular disease $\mathbf{1 1 - 1 4}^{11}$

Lipoprotein(a) is currently emerging as a possible adjustable risk factor for cardiovascular disease. However, published data on lipoprotein(a) in Vietnamese patients is still insufficient, especially in patients with acute myocardial infarction. Therefore, in this trial, our objective was to estimate the proportion of patients with acute myocardial infarction who have serum lipoprotein(a) $\geq 50 \mathrm{mg} / \mathrm{dL}$, and to describe the correlation between high concentrations of serum lipoprotein(a) and major adverse cardiovascular events and all-cause mortality after acute myocardial infarction.

\section{METHODS}

This study was carried out in the Cardiology Department of Cho Ray Hospital, Vietnam, from January 2020 to May 2020. All patients were followed until June 2020.

\section{Study design and participants}

In this prospective cohort study, randomly selected patients diagnosed with acute myocardial infarction upon admission had blood samples collected for serum lipoprotein(a) analysis no later than 108 hours from the time of symptom onset, and no later than 36 hours from hospital admission. The serum fraction was separated from the blood sample and stored. Measurements of serum lipoprotein(a) concentration were performed weekly in the Biochemical Department of Cho Ray Hospital using an immunoturbidimetric assay with an Abbott Quantia Lp(a) kit by an Abbott ARCHITECT c16000 clinical chemistry analyzer. Participants were classified into two groups, namely the high lipoprotein(a) $[\mathrm{Lp}(\mathrm{a})]$ group (participants had serum lipoprotein $(\mathrm{a}) \geq 50 \mathrm{mg} / \mathrm{dL}$ ) and the low Lp(a) group (participants had serum lipoprotein $(\mathrm{a})<50 \mathrm{mg} / \mathrm{dL})$. Data on demographics, hematologic and biochemical blood test results, and coronary angiography results (if available) were collected. Lipoprotein(a)-adjusted LDL-C values were calculated based on the Dahlen formula (LDL-C minus $30 \%$ lipoprotein(a)'s weight) ${ }^{\mathbf{1 5}}$. Enrollment in the study did not affect treatment decisions; lipoprotein(a) results were not disclosed, and only provided to participants at discharge. All patients were followed for major adverse cardiovascular events (defined as cardiovascular-related death, nonfatal myocardial infarction, and nonfatal ischemic stroke) while in hospital and within 30 days after discharge. After 30 days of discharge, all-cause mortality was followed up in patients until June 30, 2020.

Patients 18 to 80 years of age, who were diagnosed with acute myocardial infarction using the Fourth Universal Definition of Myocardial Infarction ${ }^{\mathbf{1 6}}$ and admitted within 72 hours from the onset of the symptoms, were eligible for enrollment. Exclusion criteria included septic shock, end-stage cancer, cardiac arrest with clear evidence of noncardiac origin, history of any hereditary cholesterol disorder, and patients with a history of using niacin, estrogen replacement therapy, PCSK9 inhibitors, CETP inhibitors, or lipoprotein apheresis. The trial participants provided their informed consent in writing prior to enrollment.

\section{Sample size}

To estimate the proportion of acute myocardial infarction patients with serum lipoprotein(a) $\geq 50$ $\mathrm{mg} / \mathrm{dL}$, we calculated the sample size to be 163 for a 0.05 margin of error. To detect differences in the rates of significant adverse cardiovascular events between the two groups of high and low lipoprotein(a), the ttest with equal variance showed that the sample size should be 108 for $80 \%$ power.

Detailed definitions of the variables collected are presented in the Supplementary Appendix.

\section{Statistical analysis}

We used the Shapiro-Wilk test to examine the normality of our data. The results were presented as the mean \pm standard deviation for variables with normality, and as the median and interquartile range (IQR) for variables without normality. The t-test equal variance was used to compare the two groups. We performed Fisher's exact test for categorical variables if the expected value was less than six, and Pearson's chisquare test for other categorical variables.

Logarithmic rank testing was performed to assess the difference in survival between the two groups. Cox 
regression analysis was used to assess the impacts of the survival variable on independent factors. All hypotheses were tested as two tails, and a p-value $<0.05$ was considered statistically significant. Statistical analyzes were performed using IBM SPSS Statistics 26.0 software and RStudio version 3.6.2.

\section{Ethical considerations}

Patients' participation in the study was voluntary, and they were informed of the benefits and risks of participating in our study prior to enrollment. Patient information was kept confidential and used only for research purposes. Participants were informed that they could withdraw from the study at any time.

The Ethics Council approved the study on biomedical research at the University of Medicine and Pharmacy at Ho Chi Minh City on 11 October 2019, approval number 483/DHYD-HDDD, study number 19460-

DHYD.

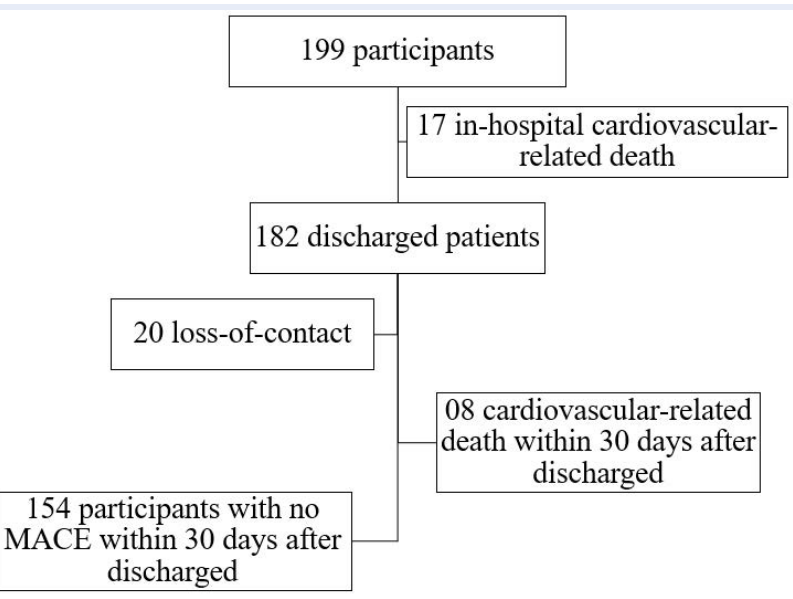

Figure 1: Summary of patients within $\mathbf{3 0}$ days af-ter discharge.

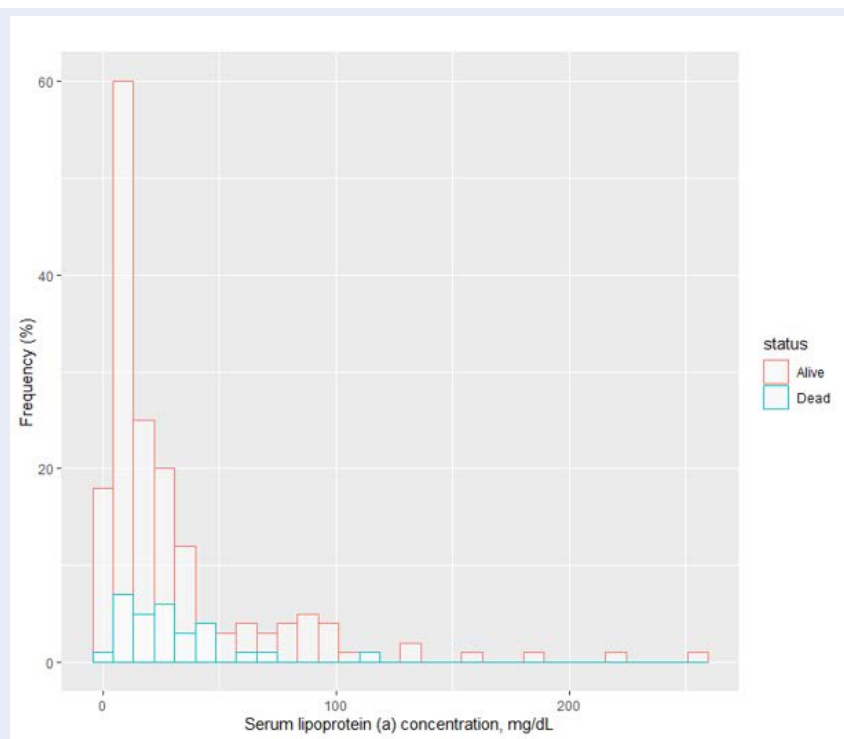

Figure 2: The histogram of serum lipoprotein(a) concentration between the status of patients. 

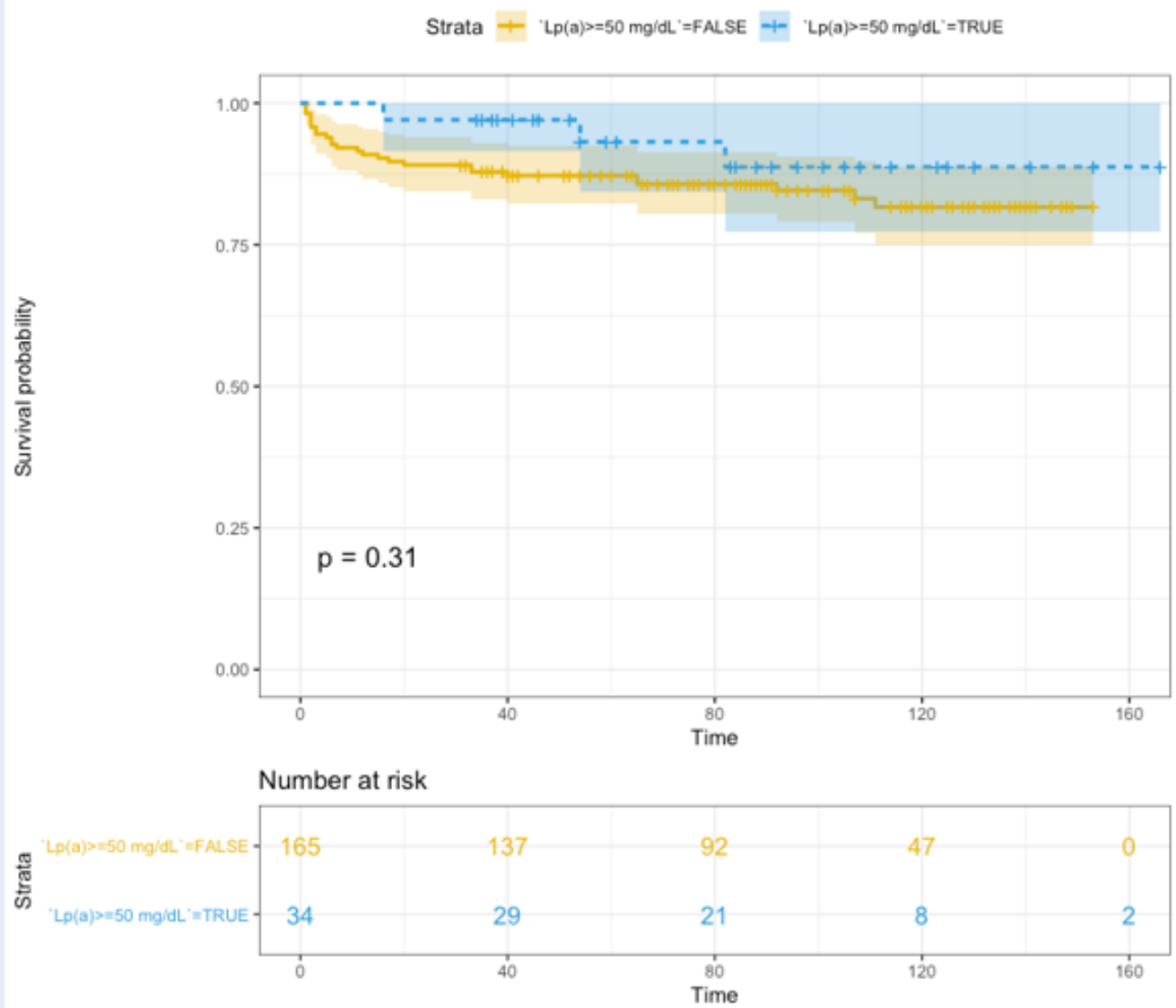

Figure 3: Kaplan-Meier curve between lipoprotein(a) $\geq 50 \mathrm{mg} / \mathrm{dL}$ and lipoprotein(a) $<50 \mathrm{mg} / \mathrm{dL}$.

Table 1: Proportions of patients with acute myocardial infarction who have different levels of serum lipoprotein(a)

\begin{tabular}{ccc}
\hline Plasma lipoprotein (a) & Percentage $(\mathbf{\%}) \mathbf{N}=\mathbf{1 9 9}$ & $\mathbf{9 5 \%} \mathbf{C I}$ \\
\hline$\geq 30 \mathrm{mg} / \mathrm{dL}$ & 29.1 & $22.8-35.5$ \\
$\geq 40 \mathrm{mg} / \mathrm{dL}$ & 20.1 & $14.5-25.7$ \\
$\geq 50 \mathrm{mg} / \mathrm{dL}$ & 17.1 & $11.9-22.3$ \\
$\geq 60 \mathrm{mg} / \mathrm{dL}$ & 14.6 & $9.7-19.5$ \\
$\geq 70 \mathrm{mg} / \mathrm{dL}$ & 12.6 & $8.0-17.2$ \\
$\geq 80 \mathrm{mg} / \mathrm{dL}$ & 10.1 & $5.9-14.2$ \\
$\geq 90 \mathrm{mg} / \mathrm{dL}$ & 6.5 & $3.1-10.0$ \\
$\geq 180 \mathrm{mg} / \mathrm{dL}$ & 1.5 & - \\
\hline
\end{tabular}


Table 2: Demographic and clinical characteristics of patients according to the level of $L p(a)$

\begin{tabular}{|c|c|c|c|c|}
\hline Variables & All $(N=199)$ & $\begin{array}{l}\text { High } \mathrm{Lp}(\mathrm{a}) \text { group } \\
\quad(\mathrm{n}=34)\end{array}$ & $\begin{array}{l}\text { Low Lp(a) group } \\
\quad(n=165)\end{array}$ & P-value \\
\hline Age, years (IQR) & $63.0(54.0-70.0)$ & $57.0(52.5-69.3)$ & $64.0(55.0-71.0)$ & 0.074 \\
\hline Female, n (\%) & $71(35.7)$ & $12(35.3)$ & $59(35.8)$ & 0.959 \\
\hline BMI, kg/m2 (IQR) & $22.9(20.8-24.6)$ & $23.9(22.1-25.5)$ & $22.5(20.8-24.4)$ & 0.040 \\
\hline \multicolumn{5}{|c|}{ Risk factors, cardiovascular history and comorbidities } \\
\hline Current smoking, n (\%) & $98(49.2)$ & $15(44.1)$ & $83(50.3)$ & 0.511 \\
\hline Arterial hypertension, n (\%) & $103(51.8)$ & $16(47.1)$ & $87(52.7)$ & 0.547 \\
\hline Diabetes mellitus, n (\%) & $58(29.1)$ & $7(20.6)$ & $51(30.9)$ & 0.228 \\
\hline $\begin{array}{l}\text { Family member with prema- } \\
\text { ture coronary heart disease, } \mathrm{n} \\
(\%)\end{array}$ & $11(5.5)$ & $1(2.9)$ & $10(6.1)$ & 0.694 \\
\hline Myocardial infarction, n (\%) & $14(7.0)$ & $2(5.9)$ & $12(7.3)$ & 1.000 \\
\hline $\begin{array}{l}\text { Percutaneous coronary in- } \\
\text { tervention, } \mathrm{n}(\%)\end{array}$ & $4(2.0)$ & $1(2.9)$ & $3(1.8)$ & 0.530 \\
\hline $\begin{array}{l}\text { Coronary artery bypass graft } \\
\text { procedure, } \mathrm{n}(\%)\end{array}$ & $1(0.5)$ & $0 \%$ & $1(0.6)$ & 1.000 \\
\hline Stroke, n (\%) & $20(10.1)$ & $2(5.9)$ & $18(10.9)$ & 0.537 \\
\hline Heart failure, n (\%) & $12(6.0)$ & $0(0)$ & $12(7.3)$ & - \\
\hline $\begin{array}{l}\text { Chronic kidney disease grade } \\
\geq 3 \text { (KDIGO) , } \mathrm{n}(\%)\end{array}$ & $5(2.5)$ & $0(0)$ & $5(3.0)$ & - \\
\hline \multicolumn{5}{|l|}{ Presentation at admission } \\
\hline $\begin{array}{l}\text { Duration from symptom on- } \\
\text { set to hospital admission, } \\
\text { hours (IQR) }\end{array}$ & $12.3(6.3-22.7)$ & $13.2(7.4-31.5)$ & $11.9(6.0-22.4)$ & 0.321 \\
\hline NSTEMI, n (\%) & $96(48.2)$ & $22(64.7)$ & $74(44.8)$ & 0.035 \\
\hline $\begin{array}{l}\text { Blood pressure, } \mathrm{mmHg} \\
\text { (IQR) }\end{array}$ & $120(100-130)$ & $120(100-133)$ & $120(100-130)$ & 0.106 \\
\hline Heart rate, bpm (IQR) & $79(65-93)$ & $73(65-89)$ & $79(65-94)$ & 0.606 \\
\hline Killip I, n (\%) & $121(60.8)$ & $21(61.8)$ & $100(60.6)$ & 0.900 \\
\hline Killip $\geq$ II, n (\%) & $78(39.2)$ & $13(38.2)$ & $65(39.4)$ & \\
\hline GRACE score (IQR) & $159(136-190)$ & $147(124-172)$ & $164(137-193)$ & 0.038 \\
\hline $\begin{array}{l}\text { Left ventricular ejection frac- } \\
\text { tion, \% (IQR) }\end{array}$ & $\begin{array}{l}44.0(34.0-54.0) \\
\quad(\mathrm{n}=196)\end{array}$ & $\begin{array}{l}43(34-55) \\
\quad(\mathrm{n}=33)\end{array}$ & $\begin{array}{l}44(34-54) \\
\quad(\mathrm{n}=163)\end{array}$ & 0.840 \\
\hline
\end{tabular}


Table 3: The laboratory tests and treatment characteristics of patients according to the level of $L p(a)$

\begin{tabular}{|c|c|c|c|c|}
\hline Variables & All $(\mathrm{N}=199)$ & High Lp(a) group $(n=34)$ & Low $\operatorname{Lp}(\mathbf{a})$ group $(\mathrm{n}=165)$ & P-value \\
\hline \multicolumn{5}{|l|}{ Laboratory tests } \\
\hline Duration from symptom onset to first troponin I sample received, hour (IQR) & $13.5(7.6-25.5)$ & $16.0(9.0-33.8)$ & $13.0(7.2-24.7)$ & 0.105 \\
\hline First sample Troponin I, ng/mL (IQR) & $33.4(8.4-50.0)$ & $28.7(11.9-50.0)$ & $37.3(8.4-50.0)$ & 0.563 \\
\hline Second sample Troponin I, ng/mL (IQR) & $36.1(11.8-168.1)$ & $34.4(15.0-152.9)$ & $37.3(10.2-168.5)$ & 0.683 \\
\hline Troponin I level change, ng/mL (IQR) & $29.0(6.8-194.8)$ & $23.2(8.9-178.3)$ & $34.3(6.6-199.9)$ & 0.975 \\
\hline Duration between two troponin I samples, hours (IQR) & $11.3(5.6-19.4)$ & $10.5(5.7-19.8)$ & $11.3(5.6-19.2)$ & 0.498 \\
\hline Haemoglobin, g/L & $130.0 \pm 17.7$ & $132.5 \pm 13.6$ & $129.5 \pm 18.4$ & 0.366 \\
\hline White blood cell count, G/L (IQR) & $12.4(10.1-15.8)$ & $11.6(9.9-14.0)$ & $12.6(10.1-16.0)$ & 0.191 \\
\hline Platelet count, G/L (IQR) & $261(220-301)$ & $259(217-305)$ & $261(223-301)$ & 0.802 \\
\hline Plasma creatinine, mg/dL (IQR) & $0.94(0.75-1.17)$ & $0.81(0.70-1.12)$ & $0.94(0.76-1.19)$ & 0.099 \\
\hline Plasma sodium, mmol/L (IQR) & $138(136-140)$ & $138(136-140)$ & $138(136-140)$ & 0.525 \\
\hline Plasma potassium, mmol/L (IQR) & $3.7(3.4-4.0)$ & $3.7(3.5-4.1)$ & $3.7(3.4-4.0)$ & 0.602 \\
\hline AST, U/L (IQR) & $86.0(47.0-213.5)$ & $87.0(48.5-149.5)$ & $85.5(46.3-236.5)$ & 0.648 \\
\hline ALT, U/L (IQR) & $44.0(27.5-73.5)$ & $38.0(26.5-50.5)$ & $47.5(28.0-76.0)$ & 0.131 \\
\hline Total cholesterol, mg/dL (IQR) & $179.0(147.3-209.8)(\mathrm{n}=192)$ & $207.5(162.3-228.3)(n=34)$ & $174.0(144.0-200.0)(\mathrm{n}=158)$ & 0.002 \\
\hline LDL-C, mg/dL (IQR) & $120.5(92.0-145.8)(\mathrm{n}=192)$ & $149.5(130.0-177.5)(\mathrm{n}=34)$ & $112.5(88.0-140.0)(\mathrm{n}=158)$ & $<0.001$ \\
\hline HDL-C, mg/dL(IQR) & $36.0(30.0-42.0)(\mathrm{n}=192)$ & $38.5(34.8-44.5)(\mathrm{n}=34)$ & $35.0(29.0-41.3)(\mathrm{n}=158)$ & 0.015 \\
\hline Triglyceride, mg/dL (IQR) & $156.0(102.5-233.0)(\mathrm{n}=192)$ & $48.4(27.5-59.1)(\mathrm{n}=34)$ & $41.5(34.0-53.2)(\mathrm{n}=158)$ & 0.809 \\
\hline Duration from symptom onset to lipoprotein(a) sample received, hours (IQR) & $42.7(34.0-54.0)$ & $48.4(27.5-59.1)$ & $41.5(34.0-53.2)$ & 0.326 \\
\hline Lipoprotein (a), mg/dL (IQR) & $17.8(7.8-34.6)$ & $85.4(68.2-105.2)$ & $12.9(7.0-25.0)$ & - \\
\hline Lipoprotein(a)-adjusted LDL-C, mg/dL (IQR) & $111.2(87.1-136.1)(\mathrm{n}=192)$ & $118.2(90.4-153.0)(\mathrm{n}=34)$ & $107.3(86.6-134.6)(\mathrm{n}=158)$ & 0.090 \\
\hline \multicolumn{5}{|l|}{ Medication during hospital stay } \\
\hline Aspirin, (\%) & $100 \%$ & $100 \%$ & $100 \%$ & - \\
\hline Clopidogrel, (\%) & $67.3 \%$ & $52.9 \%$ & $70.3 \%$ & 0.049 \\
\hline Ticagrelor, (\%) & $34.2 \%$ & $50.0 \%$ & $30.9 \%$ & 0.033 \\
\hline ACEi/ARB, (\%) & $91.5 \%$ & $94.1 \%$ & $90.9 \%$ & 0.742 \\
\hline Betablockers, (\%) & $47.7 \%$ & $55.9 \%$ & $46.1 \%$ & 0.296 \\
\hline
\end{tabular}




\begin{tabular}{|c|c|c|c|c|}
\hline \multicolumn{5}{|c|}{ Table 3 continued } \\
\hline Spironolactone, (\%) & $36.2 \%$ & $32.4 \%$ & $37.0 \%$ & 0.610 \\
\hline Loop diuretics, (\%) & $26.1 \%$ & $29.4 \%$ & $25.5 \%$ & 0.632 \\
\hline LMWH, (\%) & $100 \%$ & $100 \%$ & $100 \%$ & - \\
\hline NOAC, (\%) & $1.0 \%$ & $0 \%$ & $1.2 \%$ & 1.000 \\
\hline Anti-vitamin K, (\%) & $0 \%$ & $0 \%$ & $0 \%$ & - \\
\hline Statin, (\%) & $100 \%$ & $100 \%$ & $100 \%$ & - \\
\hline \multicolumn{5}{|l|}{ Coronary angiography } \\
\hline Coronary angiography with/without PCI, n (\%) & $153(76.9)$ & $27(79.4)$ & $126(76.4)$ & 0.701 \\
\hline Duration from symptom onset to coronary angiography, hours (IQR) & $62.1(12.9-107.7)(\mathrm{n}=153)$ & $77.8(17.8-110.3)(\mathrm{n}=27)$ & $56.4(10.8-107.4)(\mathrm{n}=126)$ & 0.338 \\
\hline Two-or-more-vessel disease, $\mathrm{n}(\%)$ & $62.1 \%(\mathrm{n}=153)$ & $70.4 \%(\mathrm{n}=27)$ & $60.3 \%(n=126)$ & 0.329 \\
\hline Three-vessel disease, $\mathrm{n}(\%)$ & $26.8 \%(\mathrm{n}=153)$ & $44.4 \%(\mathrm{n}=27)$ & $23.0 \%(n=126)$ & 0.023 \\
\hline Left main and/or three-vessel disease, $\mathrm{n}(\%)$ & $29.4 \%(\mathrm{n}=153)$ & $44.4 \%(n=27)$ & $26.2 \%(n=126)$ & 0.059 \\
\hline \multicolumn{5}{|l|}{ Other reperfusion therapies } \\
\hline Coronary artery ypass grafting procedure, (\%) & $1.5 \%$ & $2.9 \%$ & $1.2 \%$ & 0.432 \\
\hline Fibrinolytic, (\%) & $0 \%$ & $0 \%$ & $0 \%$ & - \\
\hline Hospital stay, day (IQR) & $6(5-8)$ & $6(5-8)$ & $6(4-9)$ & 0.558 \\
\hline
\end{tabular}

IQR: interquartile range; NSTEMI: Non-ST-elevation myocardial infarction, ACEi/ARB: angiotensin converting enzyme inhibitor or angiotensinogen receptor blocker; NOAC: noveloral anticoagulant; LMWH: Low molecular weigh theparin 


\section{RESULTS}

From January 16, 2020, to May 30, 2020, 200 patients were enrolled, and 199 patients were included in the final analysis. One patient was excluded from the analysis due to the loss of blood samples and the inability to contact the patient. Overall, 20 patients were lost to follow up after discharge (Figure 1). The median follow-up time was 88 days (IQR 54.0 - 125.0) (Figure 1 ).

Among the 199 patients who participated in the study, 128 patients $(64.3 \%)$ were male. Most of the patients belonged to the Kinh ethnic group $(195,98.0 \%)$, and had a median age of 63.0 years (IQR $54.0-70.0$ ) and a median BMI of 22.9 (IQR $20.8-24.6$ ) $\mathrm{kg} / \mathrm{m}^{2}$. The patients were born primarily in the provinces of the Mekong Delta.

Blood samples for lipoprotein(a) measurements were received a median of 42.7 hours after the onset of symptoms of myocardial infarction (IQR 34.0 - 54.0). However, serum lipoprotein(a) concentrations in patients with acute myocardial infarction did not show a normal distribution (Shapiro-Wilk $\mathrm{p}<0.001$ ), with the histogram skewed to the right (Figure 2).

Table 1 shows the proportions of patients with acute myocardial infarction and various concentrations of serum lipoprotein(a). Among the study population, 34 patients (17.1\%) had lipoprotein(a) $\geq 50 \mathrm{mg} / \mathrm{dL}$, and 3 patients (1.5\%) had very high lipoprotein(a) concentrations of $\geq 180 \mathrm{mg} / \mathrm{dL}$. Additionally, $17.19 \%$ of male patients had lipoprotein $(\mathrm{a}) \geq 50 \mathrm{mg} / \mathrm{dL}$ compared to $16.90 \%$ of female patients. Demographic and clinical characteristics are shown in Table 2. In our sample, 103 patients $(51.8 \%)$ had been diagnosed with hypertension and 58 patients $(29.1 \%)$ had been diagnosed with diabetes. Moreover, 11 patients (5.5\%) had a family member(s) with premature coronary heart disease, and 14 patients $(7.0 \%)$ had experienced a myocardial infarction. Furthermore, 4 patients $(2.0 \%)$ had undergone a coronary intervention, 1 patient $(0.5 \%)$ had undergone coronary artery bypass grafting surgery, and 20 patients $(10.1 \%)$ had experienced at least a stroke. Consequently, 12 patients $(6.0 \%)$ had been diagnosed with heart failure and 5 patients (2.5\%) had been diagnosed with stage 3 or greater significant chronic kidney disease. Results from other hematologic and biochemical tests are presented in Table 3 . Some patients may not have had all their test results collected. These cases are shown individually with a sample size $n$ in the statistical results box.

Compared to patients with serum lipoprotein $(a)<$ $50 \mathrm{mg} / \mathrm{dL}$ [low Lp(a) group], patients with serum lipoprotein(a) $\geq 50 \mathrm{mg} / \mathrm{dL}$ [high Lp(a) group] had significantly higher BMI (median 23.9 vs. 22.5, p = 0.0400 ), a higher rate of non-ST-elevation myocardial infarction (NSTEMI) (64.7\% vs. 44.8\%, p = 0.035), and a lower GRACE score (median 147 vs. 164, p $=0.038$ ). No differences in patients' medical history were found between the two groups. Total serum cholesterol, LDL-C, and HDL-C concentrations were significantly higher in the high $\mathrm{Lp}(\mathrm{a})$ group (mean total cholesterol, LDL-C, HDL-C: 207.5, 149.5, 38.5 $\mathrm{mg} / \mathrm{dL} v s .174 .0,112.5,35.0 \mathrm{mg} / \mathrm{dL} ; \mathrm{p}=0.002,<0.001$, 0.015 , respectively). After adjusting for lipoprotein(a) cholesterol using a conservative number of $30 \%$ of its weight, lipoprotein(a)-adjusted LDL-C was found to be not statistically different between the two groups (118.2 mg/dL in the high Lp(a) group vs. $107.3 \mathrm{mg} / \mathrm{dL}$, $\mathrm{p}=0.090)$. The rate of three-vessel disease was significantly higher in the high $\mathrm{Lp}(\mathrm{a})$ group (44.4\% vs. 23.0\%, p $=0.0230$ ) (Table 3). Patients in the high $\mathrm{Lp}$ (a) group were indicated for the use of ticagrelor at a higher rate compared to the low Lp(a) group (50.0\% vs. $30.9 \%, \mathrm{p}=0.033)$ and for the use clopidogrel at a lower rate $(52.9 \%$ vs. $70.3 \%, \mathrm{p}=0.049)$. Differences in the rate of aspirin use, ACEi or ARB, betablockers, spironolactone, loop diuretics, heparin, and statins between the two groups were not found. The rate of patients receiving coronary angiography, from the onset of symptoms to performance of the procedure, was not statistically different between the two groups. In addition, length of hospital stay was not statistically different between the two groups (both groups: median 6 days, $\mathrm{p}=0.558$ ).

In terms of major cardiovascular events among the 199 study patients, 17 patients $(8.5 \%)$ reported inhospital major cardiovascular events. All of these patients' deaths were cardiovascular-related and occurred a median of 3 days (IQR 2.0-13.5) after admission. Among these, male patients (7.81\%) were recorded with MACE during the study compared to $9.86 \%$ in female patients. We did not observe a statistically significant difference between the two groups of patients in the incidence of in-hospital MACE $(0 \%$ in the high $\mathrm{Lp}$ (a) group compared to $10.3 \%$ in the low $\mathrm{Lp}(\mathrm{a})$ group, $\mathrm{p}=0.084)$ or MACE after hospitalization up to 30 days of follow-up after discharge (6.7\% in the high Lp(a) group vs. $15.4 \%$ in the low $\mathrm{Lp}(\mathrm{a})$ group, $\mathrm{p}=0.206$ ). At the same time, we also found no statistically significant differences in the rate of re-hospitalization (13.3\% in the $\mathrm{Lp}$ (a) high group vs. $10.6 \%$ in the low $\operatorname{Lp}(\mathrm{a})$ group, $\mathrm{p}=0.747$ ) or unplanned follow-up visit (6.7\% in the $\mathrm{Lp}(\mathrm{a})$ high group vs. $0.8 \%$ in the low $\mathrm{Lp}(\mathrm{a})$ group, $\mathrm{p}=0.088$ ) between 
Table 4: Outcomes of study population between the HighLp(a) group and Low Lp(a) groups up to 30 days after discharged

\begin{tabular}{|c|c|c|c|c|c|}
\hline \multirow[t]{2}{*}{ Variables } & \multicolumn{2}{|c|}{ Sample size } & \multicolumn{2}{|c|}{ Number (\%) } & \multirow[t]{2}{*}{$P$ value } \\
\hline & $\begin{array}{l}\text { High Lp(a) } \\
\text { group }\end{array}$ & $\begin{array}{l}\text { Low } \operatorname{Lp}(a) \\
\text { group }\end{array}$ & $\begin{array}{l}\text { High Lp(a) } \\
\text { group }\end{array}$ & $\begin{array}{l}\text { Low } \operatorname{Lp}(a) \\
\text { group }\end{array}$ & \\
\hline In-hospital MACEs, n (\%) & 34 & 165 & $0(0 \%)$ & $17(10.3 \%)$ & 0.084 \\
\hline $\begin{array}{l}\text { MACEs since hospitalization up } \\
\text { to } 30 \text { days of follow-up after dis- } \\
\text { charge, } n(\%)\end{array}$ & 30 & 149 & $2(6.7 \%)$ & $23(15.4 \%)$ & 0.206 \\
\hline $\begin{array}{l}\text { Rehospitalizationswithin } 30 \text { days } \\
\text { after discharged, n (\%) }\end{array}$ & 30 & 132 & $4(13.3 \%)$ & $14(10.6 \%)$ & 0.747 \\
\hline $\begin{array}{l}\text { Unplanned follow-up visitwithin } \\
30 \text { days after discharged, n (\%) }\end{array}$ & 30 & 132 & $2(6.7 \%)$ & $1(0.8 \%)$ & 0.088 \\
\hline
\end{tabular}

the two groups within 30 days of follow-up after discharge (Table 4).

The relative risk associated with lipoprotein(a) $\geq 50$ $\mathrm{mg} / \mathrm{dL}$ and MACE following hospitalization up to 30 days after discharge was 2.37 (95\% CI $0.59-9.58, \mathrm{p}$ $=0.20$ ) and not statistically significant. The adjusted hazard ratio for GRACE score 1.026 (95\% CI 1.017 - 1.034, p < 0.001), was statistically significant. The Kaplan-Meier survival plots of the high Lp(a) group and the low $\mathrm{Lp}(\mathrm{a})$ group were not clearly separated (Figure 3). The survival difference between the two groups was not statistically significant, $\nabla^{2}(1)=1.31$, $\mathrm{p}=0.31$. The hazard ratio for lipoprotein $(\mathrm{a}) \geq 50$ $\mathrm{mg} / \mathrm{dL}$ and all-cause mortality was 0.50 (95\% CI 0.20 - 1.80) and was not statistically significant. Although we did not find statistically significant odds ratios between gender and MACE (odds ratio $=0.98, \mathrm{p}=$ 0.9590), the hazard ratio for females with MACE compared to males was $4.88(\mathrm{p}<0.0001)$.

\section{DISCUSSION}

In this study, which was conducted in the context of the COVID-19 pandemic, we believe that our study population had some selection bias, in that the proportion of patients not referred to Cho Ray hospital may have increased, especially for NSTEMI patients who did not wish to have coronary angiography. Patients with mild symptoms could be admitted later and the proportion of patients with severe symptoms may have increased.

In patients with acute myocardial infarction, lipoprotein(a) concentrations had a right-skewed histogram, in line with other studies globally. Although direct comparison is difficult due to the lack of consistent results between different methods of measurement ${ }^{2}$, the median serum lipoprotein(a) concentration was higher than that of the general populations of Chinese and Japanese individuals (12.9 and $13.1 \mathrm{mg} / \mathrm{dL}$, respectively ${ }^{17}$ ).

In our study population the proportion of patients with acute myocardial infarction and serum lipoprotein(a) $\geq 30 \mathrm{mg} / \mathrm{dL}$ was $29.1 \%$, and the proportion with serum lipoprotein(a) $\geq 50 \mathrm{mg} / \mathrm{dL}$ was $17.1 \%$, which is quite remarkable. This result was similar to that report in a study by Buuren et al. on a population with coronary artery disease, in which $26.6 \%$ of patients had lipoprotein (a) concentrations $>30$ $\mathrm{mg} / \mathrm{dL}$ and $18.4 \%$ of patients had lipoprotein(a) $>50$ $\mathrm{mg} / \mathrm{dL}^{18}$.

When comparing patients with acute myocardial infarction and serum lipoprotein(a) $\geq 50 \mathrm{mg} / \mathrm{dL}$ with patients whose serum lipoprotein(a) is $<50 \mathrm{mg} / \mathrm{dL}$, our study found that patients in the high Lp(a) group were more likely to have NSTEMI and less likely to have STEMI compared to patients in the low Lp(a) group. If we had used $30 \mathrm{mg} / \mathrm{dL}$ as the cutoff value, the result would not have been statistically significant (the NSTEMI rates in the high and low Lp(a) groups were $58.6 \%$ and $44 \%$, respectively, $\mathrm{p}=0.060$ ). Our study also found that the GRACE score was lower in the high $\mathrm{Lp}$ (a) group, but not statistically significant.At the time of writing, we could not find similar findings in other publications, in part due to the difference in cutoff values.

Coronary angiography resulted in a higher rate of three-vessel disease in the high Lp(a) group, suggesting that exposure to high concentrations of lipoprotein(a) may have caused a significant plaque burden in all coronary vessels.

Our study did not find correlations between increased lipoprotein(a) concentrations and major adverse cardiovascular events, both in-hospital and up to 30 days 
of follow-up after hospital discharge. We also found no association between increased lipoprotein(a) concentrations and the risk of death from all causes during the 6-month study follow-up (HR $=0.5,95 \% \mathrm{CI}$ 0.2-1.8). Christian Roth et al. and Baris Gencer et al. reported similar findings, although different cutoff values were used $(15,30,60 \mathrm{mg} / \mathrm{dL}$ in the study by Christian Roth et al. and $30 \mathrm{mg} / \mathrm{dL}$ in the study by Baris Gencer et al.) ${ }^{\mathbf{1 9 , 2 0} \text {. }}$

In summary, although an association between elevated serum lipoprotein(a) concentrations and cardiovascular diseases in patients who have had acute coronary syndrome or acute myocardial infarction has been shown, this association is not robust. Our study and the studies by Christian Roth et al. and Baris Gencer et al. have found that this association is not statistically significant $\mathbf{1 9 , 2 0}$. We hypothesize that the lack of statistical significance may be due to the short follow-up time, a less-selective target population, or an inappropriate cutoff value for lipoprotein(a). Interpretation of the results may also be a factor: currently, elevated lipoprotein(a) is considered a cardiovascular risk factor similar to other nonmodifiable risk factors. A more robust conclusion that lipoprotein(a)-lowering treatment reduces the risk of cardiovascular events, may need confirmation from further trials, notably the lipoprotein(a) HORIZON study.

Our study has some limitations. First, this is a singlecenter study with a limited sample size. However, this is the first study to evaluate the association of lipoprotein(a) in Vietnamese patients with acute myocardial infarction. Second, the follow-up time was relatively short, and may not have been sufficient for enough events to occur and to increase the statistical validity of the analysis. Fewer reports found an association between lipoprotein(a) and MACE at a longer postdischarge follow-up at 1 year and 3 years ${ }^{21,22}$. Therefore, further studies with larger sample sizes, multicenters, and longer follow-up times are needed. Additionally, our endpoint at follow-up was all-cause mortality, and we did not report other data such as cardiovascular death, stroke, urgent coronary revascularization.

\section{CONCLUSIONS}

Patients with acute myocardial infarction with concentrations of serum lipoprotein (a) $\geq 50 \mathrm{mg} / \mathrm{dL}$ were more likely to have NSTEMI and lower GRACE scores. Lipoprotein(a) $\geq 50 \mathrm{mg} / \mathrm{dL}$ at the time of acute myocardial infarction was not associated with in-hospital MACE or 30-day-after-discharge MACE, nor with all-cause mortality within 6 months of study follow-up. A multi-center study with a larger sample size, and long-term follow-up is needed to evaluate with greater confidence the association between lipoprotein(a) and MACE.

\section{ABBREVIATIONS}

95\% CI: 95\% confident interval, HDL: high-density lipoprotein, HDL-C: high-density lipoprotein cholesterol, IDL: intermediate-density lipoprotein, IQR: interquartile range, LDL: low-density lipoprotein, LDLC: low-density lipoprotein cholesterol, MACE: major cardiovascular adverse events, NSTEMI: non-STelevation myocardial infarction, VLDL: very lowdensity lipoprotein

\section{ACKNOWLEDGMENTS}

This study was conducted at the Cardiology Department, Cho Ray Hospital. We want to thank the medical staff who helped with the data collection.

\section{AUTHOR'S CONTRIBUTIONS}

Study design: Hoang Van Sy, Hai Phuong Nguyen Tran; Collect data: Tra Thanh Ngo, Huu Nhat Minh Le; Analysis: Khoa Le Anh Huynh, Nguyen Minh Kha, Hoang Van Sy, Hai Phuong Nguyen Tran, Quang Duy Dang Pham; Manuscript: Khoa Le Anh Huynh, Nguyen Minh Kha, Hoang Van Sy, Hai Phuong Nguyen Tran, Quang Duy Dang Pham, Hoang Van Sy, Hai Phuong Nguyen Tran, Huu Nhat Minh Le, Tra Thanh Ngo; Supervisor: Hoang Van Sy, Hai Phuong Nguyen Tran. All authors read and approved the final manuscript.

\section{FUNDING}

None.

\section{AVAILABILITY OF DATA AND MATERIALS}

Data and materials used and/or analyzed during the current study are available from the corresponding author on reasonable request.

\section{ETHICS APPROVAL AND CONSENT TO PARTICIPATE}

This study was conducted in accordance with the amended Declaration of Helsinki. The Ethics Council approved the study on biomedical research at the University of Medicine and Pharmacy at Ho Chi Minh City on 11 October 2019, approval number 483/DHYD-HDDD, study number 19460-DHYD.

\section{CONSENT FOR PUBLICATION}

Not applicable. 


\section{COMPETING INTERESTS}

The authors declare that they have no competing interests.

\section{REFERENCES}

1. Mach F, Baigent C, Catapano AL, Koskinas KC, Casula M, Badimon L, et al. 2019 ESC/EAS Guidelines for the management of dyslipidaemias: lipid modification to reduce cardiovascular risk. European Heart Journal. 2020;41(1):111-88. PMID: 31504418. Available from: 10.1093/eurheartj/ehz455.

2. Wilson DP, Jacobson $T A$, Jones $P H$, Koschinsky ML, McNeal CJ, Nordestgaard BG. Use of Lipoprotein(a) in clinical practice: A biomarker whose time has come. A scientific statement from the National Lipid Association. Journal of Clinical Lipidology. 2019;13(3):374-92. PMID: 31147269. Available from: 10.1016/ j.jacl.2019.04.010.

3. Berg K. A new serum type system in man-The Lp system. Acta Pathologica et Microbiologica Scandinavica. 1963;59(3):36982. PMID: 14064818. Available from: 10.1111/j.1699-0463. 1963.tb01808.x.

4. Nordestgaard BG, Chapman MJ, Ray K, Borén J, Andreotti F, Watts GF, et al. Lipoprotein(a) as a cardiovascular risk factor: current status. European Heart Journal. 2010;31(23):2844-53. PMID: 20965889. Available from: 10.1093/eurheartj/ehq386.

5. Tsimikas S. A Test in Context: Lipoprotein(a): Diagnosis, Prognosis, Controversies, and Emerging Therapies. Journal of the American College of Cardiology. 2017;69(6):692-711. PMID: 28183512. Available from: 10.1016/j.jacc.2016.11.042.

6. Tsimikas S, Fazio S, Ferdinand KC, Ginsberg HN, Koschinsky ML, Marcovina SM. NHLBI Working Group Recommendations to Reduce Lipoprotein(a)-Mediated Risk of Cardiovascular Disease and Aortic Stenosis. Journal of the American College of Cardiology. 2018;71(2):177-92. PMID: 29325642. Available from: 10.1016/j.jacc.2017.11.014.

7. Nordestgaard BG, Langsted A. Lipoprotein (a) as a cause of cardiovascular disease: insights from epidemiology, genetics, and biology. Journal of Lipid Research. 2016;57(11):1953-75. PMID: 27677946. Available from: 10.1194/jlr.R071233.

8. Boffa MB, Stranges S, Klar N, Moriarty PM, Watts GF, Koschinsky ML. Lipoprotein(a) and secondary prevention of atherothrombotic events: A critical appraisal. Journal of Clinical Lipidology. 2018;12(6):1358-66. PMID: 30316749. Available from: 10.1016/j.jacl.2018.08.012.

9. Willeit P, Ridker PM, Nestel PJ, Simes J, Tonkin AM, Pedersen TR. Baseline and on-statin treatment lipoprotein(a) levels for prediction of cardiovascular events: individual patient-data meta-analysis of statin outcome trials. Lancet. 2018;392(10155):1311-20. PMID: 30293769. Available from: 10.1016/S0140-6736(18)31652-0.

10. Tsimikas S, Karwatowska-Prokopczuk E, Gouni-Berthold I, Tardif JC, Baum SJ, Steinhagen-Thiessen E, et al. Lipoprotein(a) Reduction in Persons with Cardiovascular Disease. The New England Journal of Medicine. 2020;382(3):244-55. PMID:
31893580. Available from: 10.1056/NEJMoa1905239.

11. Langsted A, Nordestgaard BG. Antisense Oligonucleotides Targeting Lipoprotein(a). Current Atherosclerosis Reports. 2019;21(8):30. PMID: 31111240 . Available from: 10.1007/ s11883-019-0792-8.

12. Boffa MB, Koschinsky ML. Therapeutic Lowering of Lipoprotein(a): A Role for Pharmacogenetics? Circulation Genomic and Precision Medicine. 2018;11(2):e002052. PMID: 29449330 Available from: 10.1161/CIRCGEN.118.002052.

13. Sabatine MS, Giugliano RP, Keech AC, Honarpour N, Wiviott SD, Murphy SA, et al. Evolocumab and Clinical Outcomes in Patients with Cardiovascular Disease. The New England Journal of Medicine. 2017;376(18):1713-22. PMID: 28304224. Available from: 10.1056/NEJMoa1615664.

14. Schwartz GG, Steg PG, Szarek M, Bhatt DL, Bittner VA, Diaz R, et al. Alirocumab and Cardiovascular Outcomes after Acute Coronary Syndrome. The New England Journal of Medicine. 2018;379(22):2097-107. PMID: 30403574. Available from: 10. 1056/NEJMoa1801174.

15. McNeal CJ. Lipoprotein(a): its relevance to the pediatric population. Journal of Clinical Lipidology. 2015;9(5):57-66. PMID: 26343213. Available from: 10.1016/j.jacl.2015.07.006.

16. Thygesen K, Alpert JS, Jaffe AS, Chaitman BR, Bax JJ, Morrow $D A$, et al. Fourth Universal Definition of Myocardial Infarction (2018). Circulation. 2018;138(20):e618-51. PMID: 30571511. Available from: 10.1161/CIR.0000000000000617.

17. Guan W, Cao J, Steffen BT, Post WS, Stein JH, Tattersall MC. Race is a key variable in assigning lipoprotein(a) cutoff values for coronary heart disease risk assessment: the MultiEthnic Study of Atherosclerosis. Arteriosclerosis, Thrombosis, and Vascular Biology. 2015;35(4):996-1001. PMID: 25810300. Available from: 10.1161/ATVBAHA.114.304785.

18. van Buuren F, Horstkotte D, Knabbe C, Hinse D, Mellwig KP. Incidence of elevated lipoprotein (a) levels in a large cohort of patients with cardiovascular disease. Clinical Research in Cardiology Supplements. 2017;12(1):55-9. PMID: 28229283. Available from: 10.1007/s11789-017-0087-y.

19. Roth C, Krychtiuk KA, Gangl C, Schrutka L, Distelmaier K, Wojta J. Lipoprotein(a) plasma levels are not associated with survival after acute coronary syndromes: an observational cohort study. PLoS One. 2020;15(1):e0227054. PMID: 31917789. Available from: 10.1371/journal.pone.0227054.

20. Gencer B, Rigamonti F, Nanchen D, Vuilleumier N, Kern I, Aghlmandi S. Prognostic value of elevated lipoprotein(a) in patients with acute coronary syndromes. European Journal of Clinical Investigation. 2019;49(7):e13117. PMID: 30937890. Available from: 10.1111/eci.13117.

21. O'Donoghue ML, Fazio S, Giugliano RP. Lipoprotein(a), PCSK9 inhibition and cardiovascular risk: insights from the FOURIER trial. Circulation. 2018;275:e9-10.

22. Gencer B, Rigamonti F, Nanchen D, Vuilleumier N, Kern I, Aghlmandi S. Prognostic value of elevated lipoprotein(a) in patients with acute coronary syndromes. European Journal of Clinical Investigation. 2019;49(7):e13117. PMID: 30937890. Available from: 10.1111/eci.13117. 
Ready to submit your manuscript? Choose Biomedpress and benefit from:

- Fast, convenient online submission

- Through peer-review by experienced researchers

- Rapid publication on acceptance

- Free of charge (without publication fees)

Learn more http://www.biomedpress.org/journals/
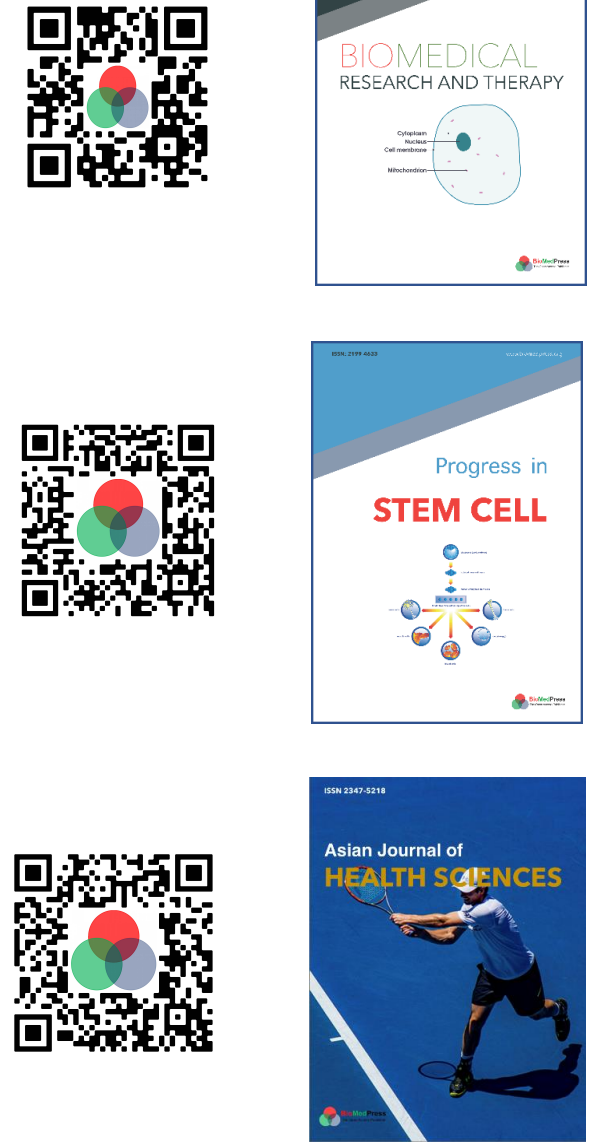

Asian Journal of Health Sciences

ISSN: 2347-5218

Indexed: Google Scholar

Acceptance Rate (2020): 72.89\%

Article Publishing Charge: Free

Submission to first editorial decision: 16.5 days

Biotechnological Research

ISSN: 2395-6763

Indexed: Google Scholar

Acceptance Rate (2020): $67.02 \%$

Article Publishing Charge: Free

Submission to first editorial decision: 28.5 days 